\title{
The Emerging Role of the Yeast Torulaspora delbrueckii in Bread and Wine Production: Using Genetic Manipulation to Study Molecular Basis of Physiological Responses
}

\author{
Andreia Pacheco, Júlia Santos, Susana Chaves, Judite Almeida, \\ Cecília Leão and Maria João Sousa
}

Additional information is available at the end of the chapter

http://dx.doi.org/10.5772/46024

\section{Introduction}

Saccharomyces cerevisiae is the yeast primarily responsible for both grape must and bread fermentation and has been used for centuries in wine and bread making. Commercial yeasts utilized by these industries are essentially strains of $S$. cerevisiae that have been selected and optimized for these applications. Nowadays, the desire to produce consumer-directed wines and bread of differentiated styles has led to the emergence of new standard selection criteria for desirable yeast strains and has expanded the selection of yeasts to other environments and to non-Saccharomyces species $(1,2)$. In this context, strains of Torulaspora delbrueckii display particular traits that have caught the attention of the bread and wine industries. However, commercial exploitation of $T$. delbrueckii in wine production has only recently begun, and this yeast is not yet used consistently in the bread industry, apart from Japan (3). This is mainly due to the lack of knowledge of its genetic and physiological background, particularly when compared to S. cerevisiae, the yeast traditionally used and one of the beststudied microorganisms. In latest years, there has been a substantial effort to characterize $T$. delbrueckii strains potentially interesting for industrial use, especially at the physiological and biochemical levels. However, there have been few studies regarding their molecular characterization, due to the lack of efficient molecular biology tools and of a sequenced genome. Two strains of interest for the bread industry have been isolated from traditional corn and rye bread dough from the North of Portugal. Both strains are potentially interesting to use in frozen dough technology due to their particularly high resistance to osmotic and freeze stress (4-6), and have been the subject of detailed studies. These studies 
focused on the characterization of traits that are relevant for a potential industrial application, such as growth rate and biomass yield on sucrose, maltose fermentative capacity, and patterns of sugar utilization and regulation when mixtures of different sugars are present (7).

Traceability is crucial in modern food technology, and it is thus essential to develop a method to discriminate between different $T$. delbrueckii strains. This would enable correct identification of the inoculated strain among the yeast flora present in bread dough or in wines. Recently, several methodologies of typing based on DNA polymorphisms that allow discriminating closely related yeast strains have been developed. Two different genetic fingerprinting techniques (karyotype analysis and mtDNA restriction analysis) have been used for detailed genotyping of T. delbrueckii strains. Mitochondrial DNA restriction analysis was not a good technique to differentiate among T. delbrueckii strains isolated from the same ecosystem that are genetically very closely related. In contrast, chromosome separation by pulsed-field gel electrophoresis revealed considerable variability in the chromosomal constitution of the strains studied, and turned out to be a useful method to discriminate among T. delbrueckii strains.

In the present chapter, we first review the current knowledge regarding the application of $T$. delbrueckii strains in the wine and bread industries, and discuss the physiological traits that make them valuable over $S$. cerevisiae. In the second part, we detail the biochemical and genetic characterization and disruption techniques used in T. delbrueckii, and conclude with future perspectives.

\section{Torulaspora delbrueckii in wine production}

\subsection{Saccharomyces cerevisiae and non-Saccharomyces species in wine making:} A brief overview

Saccharomyces cerevisiae is the yeast primarily responsible for grape must fermentation and has been used for centuries in wine making. Strains of this species are commonly found in nature on the surface of grapes and within the bioflora of wine cellars. Previous studies suggest that strains present in vats or in other winery equipment, rather than the strains found in the vineyards, are responsible for the fermentation of musts, although there is still some controversy on this subject $(8,9)$. Pure cultures of $S$. cerevisiae have been isolated from these environments and developed as starter cultures for conducting wine fermentations all over the world. Usually, start-up cultures of $S$. cerevisiae are employed to better control the fermentation process. In fact, in large scale fermentations and in the newer wine-producing countries, where a desirable natural flora may not be established in the vineyard and in the winery, there is a reluctance to rely on natural fermentation, and selected yeast cultures are inoculated into the grape must to induce fermentation $(10,11)$. Selection of strains for wine production is based on the identification of strains that can ferment grape must efficiently and produce wines of good quality. This selection is usually conducted within the genus Saccharomyces and using yeasts isolated in wine environments, particularly from cellars, 
which allow for growth of the better adapted strains $(1,12)$. Isolation of strains is followed by characterization of their traditional oenological properties (13), which are divided into technological and qualitative properties. Technological characteristics influence the efficiency of the fermentative process, while qualitative characteristics relate to the chemical composition and influence on the sensory properties of wines (1). Some of these characteristics can be evaluated by monitoring fermentation progress and by chemical analysis of the levels of compounds present at the end of fermentation (2). As these strains are marketed as dried yeast, they must also be capable of maintaining viability during the dehydration/ rehydration process (14). The desire to produce consumer-directed wines of differentiated styles has led to the emergence of new criteria when selecting yeast, such as: ability to enhance wine colour via metabolic formation of stable pigments; absence of $\beta$-glucosidase activity, ability to prevent colour degradation; facilitation of colloidal stabilization in red wines by allowing over-lees aging (to help stabilize colour); appropriate enhancement of aroma via the production of volatile compounds such as esters and higher alcohols, along with limited production of off-flavours; and the bestowing structure and body via the production of polyalcohols such as glycerol and 2,3-butanodiols, and the release of mannoproteins and yeast polysaccharides. Because it is unlikely to find $S$. cerevisiae strains with an ideal combination of oenological characteristics, it became necessary to expand the selection of strains to other environments and to non-Saccharomyces strains $(1,2)$. The latter strains cannot compete with $S$. cerevisiae under oenological conditions, but have distinct characteristics that positively influence the sensory profile of the wine. S. cerevisiae strains isolated from Parmesan cheese serum degrade malic acid present in wine musts, until $50 \%$ of its initial concentration (15). Likewise, Schizosaccharomyces pombe proved to be effective in the deacidification of must through consumption of malic acid (16-18). Candida stellata and Kloeckera apiculata produce large amounts of glycerol (19), whereas Candida colliculosa produces acetaldehyde and n-propanol (1). These positive characteristics can be used in wine production and therefore contribute to wine sensory composition. The future of this industry points to individualization of consumers based on their genetic differences and on their olfactory profiles, which will be determinant in decisions of production and marketing of wine (20).

Flavours and aromas of wines are due to the grape itself and to biological activities carried out by the microorganisms. Several species of yeasts and bacteria and sometimes filamentous fungi may be present during fermentation of the must, and are responsible for the final characteristics of the wine (1). Besides Saccharomyces, other genus such as Hanseniaspora, Kluveromyces, Candida, Metschnikowia, and Pichia are usually found. Presence and persistence of these non-Saccharomyces genera are conditioned by several factors such as temperature of fermentation, addition of nutrients, aeration, contact with the peel of the grape, nature of the Saccharomyces strain used, and inoculation practices. Other important yeasts in wine production are those responsible for wine deterioration. This category includes the genera Brettanomyces and some species of Zygosaccharomyces, Candida, and Pichia (14). The non-Saccharomyces yeasts, which also include species of Hansenula, Kloeckera, Schizosaccharomyces, and Torulaspora, are present in the early stages of fermentation, growing 
for several days until the fermentation is dominated by one or more of the S. cerevisiae strains $(13,21)$. During the initial stage of fermentation these yeasts, with low fermentation yield, produce high concentrations of long-chain alcohols, esters, aldehydes, and glycerol, which are important for the organoleptic characteristics of the wine (13). However, in the modern wine industry and particularly in large-scale production, as referred above, spontaneous fermentation is unlikely to be used due to lack of reproducibility of the wine quality. The main advantages of inoculated wine fermentations are a more rapid and even rate of fermentation and wine of more consistent quality $(11,22,23)$. On the other hand, this practice has resulted in more uniform wines without the typical contribution of aromas and flavours from indigenous yeast flora. In an attempt to change this scenario, nonSaccharomyces yeasts have recently been used in commercial wine production, particularly in countries such as the United States and Australia. This practice represents a good alternative to problems that can result from spontaneous fermentation, without compromising the sensory profile of the wine. Due to the low ethanol tolerance demonstrated by some nonSaccharomyces yeasts, inoculation of these yeasts must be performed together with a more tolerant strain that assures fermentation is completed, usually mixed starter cultures or sequential inoculation (1). Mixed starter cultures of Torulaspora delbrueckii or Kluyveromyces thermotolerans together with $S$. cerevisiae have already been tested, and revealed promising results regarding the aroma and flavour obtained (24).

\subsection{The use of Torulaspora delbrueckii in the wine industry}

The use of non-Saccharomyces wine yeasts in pure cultures as fermentation starters has shown that these have both advantages and undesirable fermentation characteristics. Among the latter, there is the production of acetic acid, ethyl acetate, acetaldehyde and acetoin at high concentrations that usually impairs the use of such strains as starter cultures. A number of authors have reported on the impact of non-Saccharomyces yeast species on wine quality under usual winemaking conditions (25-29). Torulaspora delbrueckii is reported to have a positive influence on the taste and aroma of alcoholic beverages $(19,25,26)$, at the same time exhibiting low production of acetaldehyde, acetoin, acetate, and ethyl acetate (25, 27,30 ), even in high-sugar must (31). Due to its high fermentation purity, its usage under standard conditions, in mixed or sequential culture with Saccharomyces cerevisiae, has been suggested as a strategy to reduce the acetic acid content of wine $(25,26,32)$. Even though it is a low ethanol producer, T. delbrueckii still has useful potential in sweet wine fermentation, as it does not seem to respond to osmotic stress in the same way as S. cerevisiae. For instance, mixed cultures of $T$. delbrueckii and $S$. cerevisiae have been used in pineapple wine production as a strategy for the production of a distinct flavour complexity (33). In these fermentations, volatile acidity production remained constant throughout the entire process, in contrast with fermentation carried out by S. cerevisiae, where over $35 \%$ of the total production occurs in the initial stage of fermentation. The mechanisms of osmotic resistance in $T$. delbrueckii have been investigated, but are still not completely understood and are significantly different from those of $S$. cerevisiae (34). Survival of wine strains during the 
fermentation process is also imperative for their application. Recent studies on wine ecology showed that non-Saccharomyces species survive during fermentation at significant levels for longer periods than previously thought (29). In high ethanol and moderate acetic acid concentrations, typical of stuck must fermentations, T. delbrueckii preserved its cell viability longer than S. cerevisiae (35), but on the other hand was unable to consume fructose under the same condition (35). On the contrary, S. cerevisiae presents a high fructose-consumption capacity but is much less resistant to ethanol and acetic acid. Attempting to combine the advantageous traits of these two yeasts, T. delbrueckii's high ethanol and acetic acid tolerance and the high fructose consumption capacity of $S$. cerevisiae, Santos et al (35) created a hybrid strain of the two species by protoplast fusion. This hybrid (F1-11) displayed a fructose consumption capacity comparable to that of the S. cerevisiae parent strain and exhibited increased resistance to ethanol and acetic acid, displaying a lower cell death rate under the harsh conditions present in stuck fermentations. In addition to its potential to restart stuck fermentations, this hybrid could also be useful to conduct an entire fermentation that would benefit from its flavour properties.

\section{Torulaspora delbrueckii in bread production}

\subsection{Baker's yeast and its important traits for baking applications}

In the history of human nutrition, a diversity of bakery products has been created which continues today. Bread is mostly made from flour dough that is allowed to rise (leaven) before baking in the oven. Making bread requires three main ingredients: flour, water, and yeast. The yeast's main role in the bread making process is to promptly ferment the sugars available in the flour of the dough or that have been added to it. As a result of an efficient fermentation, the yeast produces carbon dioxide $\left(\mathrm{CO}_{2}\right)$ and ethanol; the $\mathrm{CO}_{2}$ is trapped within the gluten matrix of the dough, causing the leavening or rising, while the ethanol contributes to flavour development, along with other volatile compounds and flavour precursors that are formed during the fermentation process. Technically, the most important properties of baker's yeast comprise (1) the leavening ability in the dough, (2) the ability to adapt to different carbon sources, by expressing invertase and maltase activities, and (3) stress resistance, particularly osmo- and cryo-tolerance. Obviously yeast should also contribute to the flavour of the baked products, as well as grow rapidly in molasses, which are used in the culture media in their industrial production. Commercial baker's yeasts are domesticated strains, essentially of Saccharomyces cerevisiae, that have been selected and optimized for baking applications. These particular features are the result of natural adaptation from the continuous selective pressure generated by yeast manufacturers for many years. However, some parameters are still far from optimal. Fermentative capacity is one of the most important biotechnological challenges in the baking industry. Yeast's gassing rate is crucial in baking technology and mostly depends on characteristics of baker's yeast. Tolerance to different stresses, like osmotic or freezing, is also clearly insufficient. Baker's yeast cells subjected to osmotic stress dehydrate rapidly, which limits growth and gas-production capacity $(36,37)$. Consequently, proofing time (the period where the yeast is 
allowed to leaven or raise the dough) increases and the bread volume is reduced. In frozen-sweet dough, freezing and thawing further reduce the water activity, aggravating this situation. Furthermore, freezing and frozen storage of dough has a negative impact on the baking performance due to cell damage $(36,37)$. Therefore, developing yeast strains with better gassing power in frozen and frozen-sweet dough is of great economic interest.

The physiological requirements of baker's yeast for optimal production and application represent an apparent contradiction (Figure 1). In fact, sugar-limited respiro-fermentative fed batch cultivation (yeast production phase) must render a yeast product that has developed a high fermentative capacity, although this requirement is not important during this phase. Subsequently, the gassing capacity (fermentation) is used in the application phase in the dough, under anaerobic, excess sugar conditions. Therefore the physiological flexibility of baker's yeast must be exceptional.

In addition to good fermentative capacities and high stress resistance, another major trait must be considered when selecting a yeast strain for the baking industry (38): effective biomass production in molasses. Because molasses are cheap and easily available and contain some nitrogen and several vitamins and minerals necessary for yeast growth, they are the main substrate used for large-scale baker's yeast production. However, molasses are considered a major factor of variation in the quality of baker's yeast (39). These substrates are highly variable and contain different proportions of sugars. Though sucrose is the major sugar present, there is also a quite high amount of glucose and fructose. Sucrose is cleaved outside the cell by invertase into glucose and fructose. Invertase is also capable of cleaving raffinose, a trisaccharide also present in molasses, into fructose and melibiose (glucose-galactose), but melibiose is generally not assimilated (40). The main fermentable sugar in plain bread dough is maltose, liberated from starch by amylase activity ( $\alpha$-glucosidase) in flour. This disaccharide is transported through a maltose permease and is subsequently hydrolyzed into glucose by maltase (figure 2). The order by which these different carbohydrates are fermented by S. cerevisiae is not random; rather, it is based on a specific hierarchy, with glucose being the preferred sugar. Consequently, in dough containing glucose, sucrose, and maltose, the disaccharides are fermented only when all the glucose is consumed. The monosaccharides glucose, fructose, and mannose are transported into cells across the plasma membrane by hexose transporter $(\mathrm{Hxt})$ proteins, and are subsequently further metabolized in glycolysis. The endpoint of glycolysis is pyruvate, and whether it is used for respiration or fermentation depends on the growth conditions. When cells are grow in an anaerobic environment, sugars are fermented into $\mathrm{CO}_{2}$ and ethanol. However, cells are also able to use glucose for fermentation when grown aerobically if glucose is present at high concentrations. This phenomenon is generally referred to as the Crabtree effect $(42,43)$. In an aerobic environment, glucose is catabolized exclusively through respiration only when cells are grown in low sugar concentrations. In addition to being the favourite carbon source for yeast, glucose controls different mechanisms that ensure its primary utilization, as well as general regulation of metabolism, cell growth, and development. 


\section{BAKER'S YEAST}

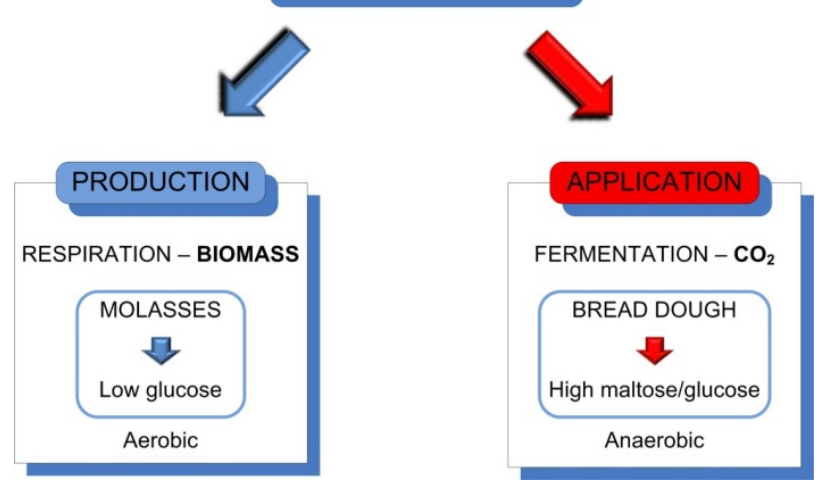

Figure 1. Baker's yeast production and application paradox. Baker's yeast must be able to readily ferment sugar to $\mathrm{CO}_{2}$ (and ethanol) in doughs. At the same time it must grow on molasses in sugar-limited respiro-fermentative fed batch cultivations for yeast production. Therefore, when the metabolic flux is directed toward cell growth and biomass production, yeast is expected to display a good fermentative capacity. Adapted from (41).

For the most part, regulation is mediated by catabolite repression, acting at early steps in various catabolic pathways. The aim of the regulation is to induce utilization of most favoured carbon source (glucose), and to exclude utilization of other carbon sources if a sufficient amount of glucose is available. Therefore, in most strains of S. cerevisiae, glucose represses genes responsible for maltose transport and hydrolysis, as well as invertase that hydrolyzes sucrose to glucose and fructose (42). Although high levels of invertase activity are required for growth in molasses, there is evidence that the capacity of S. cerevisiae to ferment high sucrose concentrations, like those present in sweet bread doughs, is inversely related to the activity of this enzyme (43).

\subsection{Torulaspora delbrueckii as an emergent yeast in the baking industry}

Nowadays, the baker's yeast strains used have been developed as a result of centuries of experience and selection, resulting in a high degree of domestication best suited for bread making. Nevertheless, research to improve yeast strains continues. Although methods of classical genetics (selection, mutation, and hybridization) are still very useful, novel methods such as protoplast fusion and genetic engineering have resulted in baker's yeast strains with even better technological properties $(35,37,44)$. Saccharomyces cerevisiae strains are generally used as baker's yeast, nevertheless the use of alternative species in bread making may allow coping with the new and more demanding challenges in the baking industry. Dough leavening ability has been reported for yeast other than S. cerevisiae. Issatchenkia orientalis, Pichia membranaefaciens, and Torulaspora delbrueckii were the most abundant non-Saccharomyces species present in homemade corn and rye bread dough $(6,45)$. Among them, the biotechnological interest in T. delbrueckii has increased in recent years due to its particularly high freezing and osmotic tolerance 
$(4,5,46)$. Thus, some T. delbrueckii strains are commercialized in Japan for regular $(5 \%$ sucrose) frozen dough applications (47). In rural areas of Portugal, bread is sometimes prepared with dough carried over from a previous making. Following an isolation program of yeasts from homemade corn and rye bread doughs, two strains of $T$. delbrueckii, PYCC 5321 and PYCC 5323, were selected on the basis of simultaneously combining high growth rates and leavening ability, characteristics desirable in baker's yeast, as well as an exceptional freeze tolerance (6). The leavening activity of $T$. delbrueckii PYCC 5321 and PYCC 5323 upon freeze-thaw appeared to be unaltered, in contrast with the decrease of fermentative capacity of $S$. cerevisiae baker's yeast (4). In addition, these report from Almeida and Pais (1996b) (4) showed that T. delbrueckii strains are not affected by a period of fermentation before freezing. This yeast also displayed higher leavening ability than S. cerevisiae, under conditions of hyperosmotic stress in bread dough containing $20 \%$ sucrose and $2 \%$ salt (46). This feature is in agreement with a low invertase activity, a slow rate of trehalose mobilisation and the ability to respond rapidly to osmotic stress. In summary, T. delbruecckii strains studied gather the most important traits needed in a baker's yeast as rapid growth, high biomass, a high leavening activity in lean and frozen dough and extend these properties to sweet and frozen sweet dough. Thus, application of these strains in bread making would have additional advantages, since a single strain can be used for most or all baking applications with the highest performance.

Although this yeast is widely commercialized in Japan, the regular utilization of this species in the bread-making industry has not been established due to several drawbacks. $T$. delbrueckii strains are usually resistant to osmotic stress, but they show considerable variation in their abilities to ferment and to assimilate carbon compounds, as galactose or maltose (48), as well as variable maltase activity and fermentative capacity (46). Moreover, its small cell size is a major disadvantage in the industrial dehydration process, as filtration of cells for dehydration requires a long time and, even worse, cannot be performed continuously because the filter used for dehydration becomes clogged and must be changed frequently (49). Additionally, there is a lack of knowledge on the physiology and molecular biology of this yeast. Despite its phylogenetic closeness to S. cerevisiae, the differences observed between the two species demonstrate that the behaviour of T. delbrueckii cannot be directly inferred from that of $S$. cerevisiae.

\section{Sugar metabolism in Torulaspora delbrueckii}

As referred above, Torulaspora delbrueckii is an important case study among the non-Saccharomyces yeast species, of particular relevance to the baking and wine industries. In order to better evaluate the potential offered by T. delbrueckii, several physiological and biochemical studies have been carried out with this yeast. In particular, our group studied sugar utilization patterns, maltase and invertase activities, respiration/fermentation rates, and sugar uptake, thus contributing to a better understanding of the mechanisms underlying regulation of sugar metabolism in this yeast. 


\subsection{Sugar utilization patterns and respiro-fermentative metabolism}

One of the leading characteristics of a valuable baker's yeast is its dough-leavening ability, which implies there is efficient fermentation of both the maltose and glucose that are present in the dough. Another important feature is its ability to generate high biomass yields on sucrose, the major sugar present in molasses. On the other hand, glucose and fructose are the main sugars present in grape musts, and thus efficient fermentation of these sugars is also of great importance for utilization of a yeast strain in wine fermentation.

The behavior of T. delbrueckii PYCC 5321 in Yeast Peptone (YP) medium with glucose, sucrose, and maltose, either as single carbon and energy source or in mixtures, has been compared with that of a commercial baker's yeast, used as reference (7). When single-sugar media were used, the growth rate of both yeasts was similar in both glucose and sucrosecontaining media and slightly lower in maltose-containing medium. For Saccharomyces cerevisiae, these values were similar to those obtained in mixed-sugar media, but for $T$. delbrueckii the values obtained in mixed-sugar media with maltose (Glucose-Maltose (G-M) and Sucrose-Maltose (S-M) mixtures) were again slightly lower. Since analysis of the specific sugar consumption rates and transport capacities suggested that sugar transfer rates into the cell limit fermentation efficiency (50), the lower growth rates obtained in the presence of maltose were probably a result of inhibition of glucose uptake by maltose, which is known to occur in both S. cerevisiae (51) and T. delbrueckii (7). In G-M mixtures, maltose was consumed only after glucose was exhausted from the medium, and the increase in maltose transport and maltase activities clearly correlated with the beginning of maltose consumption. Therefore, it seems that the maltose transporter and maltase are co-regulated, and are subject both to induction by maltose and to repression by glucose. On the contrary, commercial baker's yeast began to consume maltose when glucose was still available, suggesting glucose control over maltose metabolism is higher in $T$. delbrueckii than in commercial baker's yeast. Under laboratory conditions, this distinct performance of the two species could imply an unwanted delay in $\mathrm{CO}_{2}$ production in maltose-containing bread dough by T. delbrueckii. However, this apparent advantage of $S$. cerevisiae is counteracted by the higher osmotolerance of T. delbrueckii under the conditions prevailing in bread dough. In S-M mixtures, maltose consumption is also inhibited until sucrose is exhausted, although this inhibition is not particularly efficient and maltose levels slightly decrease concomitantly with sucrose consumption. These results suggest that glucose released from sucrose through invertase activity inhibits maltose metabolism. When cells were grown in media with either only one sugar or with mixtures of sugars as carbon sources, the invertase activities obtained were also in accordance with a regulation pattern similar to that observed in $S$. cerevisiae. In fact, while invertase activity was subject to glucose control, it was not dependent on induction by sucrose.

T. delbrueckii displayed biomass and ethanol yields typical of fermentative metabolism in all media. Despite this clear fermentative metabolism exhibited by $T$. delbrueckii in batch cultures with each of the sugars tested (glucose, maltose and sucrose), the specific rates of $\mathrm{CO}_{2}$ production and $\mathrm{O}_{2}$ consumption, estimated with the Warburg manometric technique, 
showed there was a higher contribution of respiration to the overall sugar metabolism than that observed in S. cerevisiae. It is worth noting that during batch cultivation the available oxygen rapidly reaches limiting concentrations, thereby favoring fermentative metabolism. In fact, when biomass yields were determined in YP medium containing glucose, sucrose, or maltose, using higher aeration rates resulted in a very significant increase in biomass yields (from $20 \%$ in glucose or sucrose medium to $80 \%$ in maltose medium). The more efficient modulation of the respiratory metabolism in T. delbrueckii under aerobic conditions thus represents an asset for the large-scale production of this yeast.

Aiming to provide new insights into the molecular mechanisms underlying energy source signaling in T. delbrueckii, a gene coding for a putative protein with high similarity to the $S$. cerevisiae carbon catabolic-derepressing Ser/Thr protein kinase Snf1 was recently identified, and named Tdsnf1p (52). It seems that, like Snf1p, Tdsnf1p is required for growth in ethanol, low glucose $(0.05 \%)$ and raffinose-containing medium, although in the last case the phenotype was not as pronounced as that of the S. cerevisiae snf1 $\Delta$ mutant. In contrast, the tdsnf1 $\Delta$ mutant displayed increased $\mathrm{Li}^{+}$tolerance, a phenotype not observed in the $S$. cerevisiae snf1 $\Delta$ mutant, further highlighting the differences between these two yeasts.

In summary, the overall patterns of sugar utilization and regulation in mixed sugar media by $T$. delbrueckii are equivalent to those described for $S$. cerevisiae $(42,53,54)$, though some critical differences were identified. In addition, given that specific growth and fermentation rates in maltose-containing media were lower than those obtained in glucose- and sucrosecontaining media, and that growth rate seems to be limited by transport capacity, these studies also indicated that maltose uptake is a good target for metabolic engineering and improvement of T. delbrueckii's performance in bread doughs.

\subsection{Hexose transport in Torulaspora delbrueckii}

\section{Yeast sugar transporters: a brief introduction}

The sugar porter family is the largest within the major facilitator superfamily (MFS), which includes proteins from Bacteria, Achaea, and Eukarya, with very diverse sequences and function (55-57). Proteins belonging to the MFS exhibit highly structural conservation, though they share little sequence similarity (58). Generally, these permeases have 12 putative transmembrane segments, and consist of a single integral membrane protein with two sets of six hydrophobic transmembrane-spanning (TMS) $\alpha$-helices connected by a hydrophilic loop, whose amino- and carboxy-terminal regions localize to the cytoplasm (5961). The strong similarity between the two sets of hydrophobic TMS of MFS proteins and their overall structure supports the theory that they result from a gene duplication event that probably took place before de divergence of MFS families (57, 59). Sugar transport across the plasma membrane is the first and obligatory step of its utilization. Yeasts can use different carbon sources for growth, but evolution has selected mechanisms for the preferential utilization of glucose. As permeability of biological membranes is quite restricted, most of the cellular nutrients must enter the cell via specific transport systems and both facilitated diffusion and proton-symport transport systems for sugars have been 
described in yeasts. In facilitated diffusion, solutes are transported down a concentration gradient by a uniport mechanism. Secondary active transport uses accumulated energy from an electrochemical gradient to transport molecules against their concentration gradient, coupled with the simultaneous movement of another molecule (normally $\mathrm{H}^{+}$or $\mathrm{Na}^{+}$) in the same (symport) or opposite (antiport) direction (62). Such a mechanism becomes fundamental during growth in very low extracellular sugar concentrations, when an intracellular accumulation of hexoses may be necessary to allow hexose kinases to function optimally. Evidently, yeast species possessing proton-hexose symport systems are better adapted to grow in low hexose concentrations $(63,64)$. Since a facilitated diffusion transport system is most efficient only under reasonably constant levels of the carrier substrate, this system might not be appropriate for yeasts like Saccharomyces cerevisiae. However, this yeast uptakes hexoses only by facilitated diffusion, and has clearly overcome this setback by developing an unusual diversity of hexose transporter proteins (Hxtp) with specific individual properties and kinetics (65).

Multiple hexose carriers have been characterized genetically in S. cerevisiae. Among about 5600 protein-coding genes in S. cerevisiae, at least 271 encode predicted or established permeases (66). Twenty encode hexose transporters and related proteins, the so-called HXT gene family $(60,65)$. Of these, only HXT1-HXT7 encode transporters that are important for growth and metabolism of glucose $(51,67)$. The galactose transporter, encoded by GAL2, is also a member of the HXT gene family $(68,69)$. Two members of the family, encoded by SNF3 and RGT2, have lost the ability to transport hexoses; instead they function as sensors of the extracellular glucose concentration. This glucose signal is involved in the transcriptional regulation of various $H X T$ genes (70). The remaining members of the family (HXT8-HXT17) are phenotypically silent, and may not be expressed under normal physiological conditions (51). As discussed by Wieczorke et al. (71), the large number of hexose transporter proteins in S. cerevisiae seems to reflect its adaptation to the variety of environmental conditions to which yeast cells are exposed. Two kinetically distinct glucose uptake systems were initially described in S. cerevisiae: a constitutive low-affinity system $\left(K_{m}=15-20 \mathrm{mM}\right)$ and a glucose-repressible high-affinity system $\left(K_{m}=1-2 \mathrm{mM}\right)$ (reviewed in 70). It is now considered these two components consist of several different transporters contributing to the overall kinetic properties of the systems. The affinity of the major Hxt proteins for glucose was determined by individual expression of these transporters in a $h x t$ null strain (72), and differs significantly; for example, Hxt1p and Hxt3p have a low-affinity for glucose, whereas Hxt2p, Hxt6p, and Hxt7p have a high-affinity (72). The low-affinity transporters are expressed when cells are grown in media containing high concentrations of glucose, whereas the high-affinity transporters are expressed when cells are grown in media containing low concentrations of glucose (70). It should however be noted that most of the data pertaining to the kinetics of glucose transport was obtained from individual expression of HXT genes in a hxt null mutant, and thus the results may not reflect the in vivo functions of Hxt proteins. When expressed in the absence of other Hxt proteins, an individual Hxt protein might display a different affinity for glucose, as it may be modulated by means of interactions between different Hxt proteins. Furthermore, any one HXT gene may be important for regulation of the expression of the other HXT genes $(70,73)$. 
The number of hexose transporters is very variable among yeasts, ranging from 20 hexose transporters in S. cerevisiae and Candida albicans to six in Schizosaccharomyces pombe. In silico analysis of the Kluyveromyces lactis genome (74) showed that this yeast has 20 sugar transporter genes, but only seven of them have been characterized. Based on protein sequence homology (TBLAST search) with CaHgt1, the first gene encoding a glucose transporter in C. albicans (75), 19 other putative glucose transporters were uncovered and designated Hgt2-Hgt20 (76, 77). In the fission yeast $S$. pombe, six hexose transporter genes (GHT1-GHT6) have been identified (78), which are highly similar at both the nucleotide and amino acid level. In Pichia stipitis, three genes encoding glucose transporters SUT1, SUT2 and SUT3 (sugar transporters) have been identified, which probably constitute only a subfamily of glucose transporters (79). With the complete sequencing of the $P$. stipitis genome, several additional putative sugar transporter genes were also uncovered (80). Stasyk et al. (81) described Hxt1p, the first functional hexose transporter identified in the methylotrophic yeast Hansenula polymorpha. Wei et al. (82) found at least 17 putative hexose transporters in the genome of Aspergillus nidulans. So far, only one hexose (particularly fructose) transporter has been described in S. pastorianus (83) and in Zygosaccharomyces bailii (84). Fsy1p (fructose symport) is a specific fructose/H+ symporter which mediates high-affinity fructose uptake (it does not transport glucose) in S. pastorianus (83). In Z. bailii, Ffz1p (fructose facilitator of Zygosaccharomyces) does not accept glucose as a substrate and displays low affinity for fructose (84).

\section{Hexose transport in Torulaspora delbrueckii and cloning of LGT1}

Two natural habitats of Torulaspora delbrueckii are bread doughs and fruit juices, such as grape juice, environments that are rich in sugars. As a consequence of growth and fermentation of these sugars, this yeast experiences dramatic changes in its physicochemical environment, and thus must adapt to these varying conditions in order to sustain its growth. The sugar concentration may decline from $1 \mathrm{M}$ to $10^{-5} \mathrm{M}$ during fermentation, and the overall composition of the medium will be altered by yeast metabolism. The sugar transport activity of the cell and the proteins that mediate sugar transport must be responsive to these changing conditions, and thus the capacity and kinetic complexity of hexose transport in the yeast may be a reflection of the existence of a large number of sugar transporter genes in its genome. Based on this assumption, multiple hexose transporters with different affinities for glucose probably exist in T. delbrueckii. This yeast displays a mediated glucose transport activity best fitted assuming a biphasic Michaelis-Menten kinetics with a low- (apparent $K_{m}=8.32 \pm 0.55 \mathrm{mM}$ ) and a high-affinity component (apparent $\mathrm{K}_{\mathrm{m}}=1.30 \pm 0.34 \mathrm{mM}$ ) (50). A kinetic compatible with the presence of these two components was observed in either glucose-, frutose- or maltose-grown cells. Aiming to identify glucose transporters in T. delbrueckii, a complementation screen of a $S$. cerevisiae hexose transport-null mutant strain (71) yielded a genomic DNA fragment containing a gene encoding Lgt1p, a low-affinity glucose transporter (50). When expressed in the $h x t$ null strain, Lgt1p exhibited an apparent $\mathrm{Km}$ value for glucose of $36.5 \pm 3.1 \mathrm{mM}$, in the range of the low-affinity component, and a $V_{\max }$ of $1.1 \pm 0.04 \mathrm{nmol} / \mathrm{s} / \mathrm{mg}$ dry weight. This transporter is also able to mediate significant fructose uptake in the hxt mutant, 
although with a lower affinity than that for glucose, with an apparent $\mathrm{K}_{\mathrm{m}}$ value of $51.4 \pm 3.0$ $\mathrm{mM}$. Glucose transport in this mutant (expressing Lgt1p) was inhibited by the presence of frutose, manose and maltose. Expression studies of the T. delbrueckii LGT1 gene in S. cerevisiae strains, including wild-type, using a fusion of the LGT1 promoter to the reporter gene $1 a c Z$, revealed that it was induced by high glucose concentrations, and its expression was elevated in media containing $4 \%$ glucose and almost undetectable in medium containing galactose as the sole carbon source. The transcription factor Rgt1p was necessary for repression of LGT1 in the absence of glucose; however, and in contrast with the activity of Rgt1p as a bifunctional regulator in S. cerevisiae strains, full induction of LGT1 by high glucose concentrations does not require functional Rgt1p. Even though Mig1p-binding sequences were identified in the promoter region of the LGT1 gene, the general repressor of $S$. cerevisiae had no effect in the regulation of LGT1 gene expression. However, disruption of MIG2 in a mig1 background led to high levels of LGT1 expression in high glucose concentrations, indicating that either Mig2p or both Mig1p and Mig2p acting redundantly, function as repressors of LGT1 expression under these conditions, consistently with their function in S. cerevisiae.

Even though just one glucose transporter has been identified in T. delbrueckii until now (the low-affinity glucose transporter LGT1 (50)), it is likely that T. delbrueckii possesses high-affinity transporters, which is supported by the biphasic Michaelis-Menten kinetics of glucose transport. These results suggest there are additional physiological relevant glucose transporters. Identification of novel transporters will provide new clues regarding the mechanisms underlying regulation of sugar transport, and as a consequence the fermentative capacity of this biotechnologically relevant yeast.

\subsection{Cloning and characterization of the Torulaspora delbrueckii MAL11, encoding a high-affinity maltose transporter}

The genes involved in the utilization of maltose have been characterized in detail in laboratory strains of Saccharomyces cerevisiae (85). Genetic analysis revealed there are five MAL loci, MAL1-MAL4 and MAL6, located on different chromosomes (86), but with a high degree of similarity (87). Each locus contains a set of three different genes that encode a maltose transporter (MALT - MALx1, where $\mathrm{x}$ represents the number of each locus), $\alpha$ glucosidase (MALS - MALx2), and a regulatory protein (MALR - MALx3) (53). MALx1 genes code for high affinity maltose- $\mathrm{H}^{+}$simporters with a $\mathrm{K}_{\mathrm{m}}$ of approximately $5 \mathrm{mM}(88)$, but with different specificities for various substrates. While Mal11p/Agt1p transports a wide range of substrates, including several $\alpha$-glucosides (89), Mal31p and Mal61p seem to primarily use maltose, maltotriose, and turanose $(89,90)$. Nevertheless, only one fully functional locus seems to be found in standard laboratory strains, MAL1, which is heavily regulated through repression by glucose and induction by maltose (91). Comparatively, industrial yeasts contain multiple fully or partially functional MAL loci $(92,93)$. Additional analysis showed there are considerable variations in the MALR gene (94), leading to nonsensitivity to glucose and lack of control by maltose. These special features were the result 
of applying successive programs directed to a rapid adaptation to the fermentation of maltose.

Characterization of maltose transport rates in Torulaspora delbrueckii indicated it contains an inducible active transport system that co-transports protons with maltose, with the following kinetic parameters: $V_{\max } 1.03 \pm$ of $0.05 \mathrm{nmol} \mathrm{s}^{-1}$ (mg dry weight) ${ }^{-1}$ and $\mathrm{K}_{\mathrm{m}} 2.26 \pm$ $0.27 \mathrm{mM}$ maltose (95). This transport system was subject to glucose repression and was competitively inhibited by the presence of sucrose, melizitose, and melibiose, suggesting these sugars likely share the same transporter(s) with maltose.

A DNA fragment containing the MAL11 gene from T. delbrueckii (TdMAL11) was isolated by complementation cloning in S. cerevisiae with a T. delbrueckii genomic library $(95,96)$. DNA sequence analysis revealed the presence of an ORF of 1884 bp encoding a putative 627amino acid membrane protein with 10 transmembrane domains, highly similar to other yeast maltose transporters. Upstream of TdMAL11, the DNA insert included a partial ORF (TdMAL12) on the opposite strand and direction, highly similar to the S. cerevisiae MAL12 gene. Two consensus binding sites of the repressor Mig1p (positions -362 to -378 and -459 to -475) are evident in the divergent promoter. Interestingly, the first overlaps with a binding site of a MAL activator (-451 to -461). A similar situation was described in the intergenic region MAL61-MAL62 in S. cerevisiae, where one of the two Mig1p binding sites is very close to a UASMAL site (97). This overlap seems to have a functional role in the transcriptional regulation of MAL61 and MAL62 genes, as occupation of the UASMAL site will result from direct competition between the two regulators for the binding region (98). Sequence analysis, Northern blot, and transport measurements, indicated that TdMAL11 expression is regulated by carbon source, and is subjected to repression by glucose and induction by maltose. Attempts to disrupt TdMAL11 and Southern blot analyses revealed the presence of two functional MAL loci. Disruption of a single copy decreased the $\mathrm{V}_{\max }$ of maltose transport, but not the $\mathrm{K}_{\mathrm{m}}$, whereas the double disruption abolished the uptake of this sugar in $T$. delbrueckii (95).

As referred above, the activity and regulation of the maltose uptake system in T. delbrueckii cells could be a good target for improvement of its leavening ability in bread dough, and the identification of maltose transporter genes in this yeast can now open the door to these studies.

\section{Freezing tolerance of Torulaspora delbrueckii: Cellular and biochemical basis}

\section{Baker's yeast and stress resistance}

In the baking industry, yeasts encounter numerous stresses. During production, they must adapt to low sugar and high aeration, repressing fermentation to produce large amounts of biomass. Cells are then preserved in a cold, frozen or dry state until use, when rehydration or thawing and inoculation cause osmotic shock in a new environment that 
requires the induction of enzymes for maltose utilization under semianaerobic conditions. The low stress resistance of yeast during active fermentation is disadvantageous for its use in industrial applications, and it would be highly advantageous to have yeast strains available that do not lose their stress resistance during fermentation (36). Furthermore, human food habits have changed in the past few years and there has been an increasing usage of frozen dough for bread production. Yeasts under such stress conditions reduce fermentation performance, compromising product quality $(36,99)$. Namely, reduced yeast vitality after freezing and thawing the dough causes loss of fermentation capacity and makes it necessary to use higher yeast amounts and longer proofing times (i.e., the resting period after mixing during which fermentation takes place), consequently decreasing product volume (100). As a result, these effects have a great technological and economic impact in the baking industry. Undoubtedly, the ability of baker's yeast to cope with stress conditions is an essential physiological requirement in this industry, which evidently would greatly benefit from the availability of yeast strains with improved freeze resistance.

One of the first stresses encountered by baker's yeast cells during the preparation of frozen dough is the cold-shock, i.e. the decrease in the environment temperature after mixing. This change impairs the correct functioning of both the membrane and the translational apparatus as a result of reduced membrane fluidity and stabilization of the secondary structures of DNA and RNA $(101,102)$. While positive cold temperatures lead to the synthesis of specific proteins associated with the development of transient phenotypic adaptation (103, 104), freezing is frequently a lethal stress to cells. At sub-zero temperatures, the damaging effects on yeast cells depend on the freezing rate. In the case of rapid freezing, cells are injured by the formation of intracellular ice crystals, which leads to membrane disruption (105). Structural examination of these cells shows discontinuous nuclear membranes, disappearance of vacuoles, and spreading of DNA all over the cells (106). On the other hand, in cells exposed to low freezing rates, osmotic shrinkage of the cells and frozen extracellular water is observed. Therein, cells become exposed to hyperosmotic solutions and try to compensate by moving water across the membranes (107). In this case, cells suffer cellular damage similar to that caused by dehydration. During frozen storage, the growth of ice crystals can further deteriorate the plasma membrane and damage the activity of different cellular systems. Taken together, these findings indicate that freezing is a very complex stress, in which different stress responses appear to play important roles. Therefore, freezing tolerance likely involves different mechanisms working in concert.

\section{Torulaspora delbrueckii and freezing resistance}

The high freezing resistance of T. delbrueckii PYCC 5321 and 5323 strains was the main characteristic that set them apart as potential candidates for the baking industry. In fact, even after freezing these T. delbrueckii cells at $-20{ }^{\circ} \mathrm{C}$ for at least 120 days, they retained nearly $100 \%$ cell viability, estimated as colony forming units (CFU). In contrast, viability of a Saccharomyces cerevisiae commercial baker's yeast was less than $20 \%$ viability by the $15^{\text {th }}$ 
day (5). The resistance of T. delbrueckii was due to its ability to maintain the integrity of the plasma membrane, and it diminished in the presence of cycloheximide in the freezing medium. Membrane integrity, evaluated by flow cytometry with propidium iodide staining, correlated directly with the CFU counts for both yeasts, validating the utilization of flow cytometry to measure viability of yeast cells subject to freezing stress. The ability of T. delbrueckii to preserve plasma membrane integrity during freezing does not correlate with the concentration of intracellular trehalose $\left(T_{\text {in }}\right)$ at the time of freezing, since the values of $T_{\text {in }}$ were high and in the same order of magnitude in both $T$. delbrueckii and $S$. cerevisiae strains. In addition, $T$. delbrueckii was able to retain much higher cell viability when subject to a period of fermentation before freezing. Under those circumstances, there

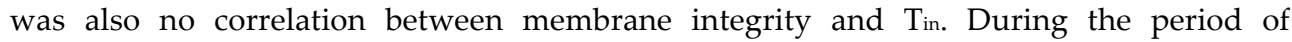
prefermentation, the concentration of $T_{\text {in }}$ fell at a high rate and to similar values in both strains, consistent with a similar pattern of activation of trehalase (s) by glucose, determined in cellular extracts of $T$. delbrueckii and S. cerevisiae. In contrast, the higher capacity to preserve the plasma membrane observed in $T$. delbrueckii seems to be related to a smaller increase of lipid peroxidation during the freeze storage period. These results suggest that the ability of $T$. delbrueckii to avoid damage from oxidative stress in the plasma membrane during freezing can contribute to its freeze-resistant phenotype. In agreement with these results, which seem to imply oxidative damage is involved in the loss of plasma membrane integrity during freezing, pre-treatment of $S$. cerevisiae cells with the radical scavenger N-tert-Butyl- $\alpha$-phenylnitrone $(\mathrm{PBN})$ led to a reduction in the loss of membrane integrity.

\section{Gene disruption in Torulaspora delbrueckii}

The use of gene deletion mutants is an important tool to decipher the role and physiological relevance of the proteins encoded by different genes. Results from these studies can increase the knowledge of the physiology, biochemistry and molecular biology of an organism. To this purpose, construction and analyses of Torulaspora delbrueckii mutant strains are of highest importance; however, the genetic tools available for this yeast are very scarce. Disruption of genes followed by phenotypic analyses is a vital tool for understanding yeast gene function. However, the efficiency of gene disruption is highly variable among species, and is often quite low for non-conventional yeasts. In yeast, gene disruption is usually accomplished by transforming cells with a gene-targeting section (cassette) containing a selectable marker, conferring drug resistance or nutrient autotrophy, flanked by upstream and downstream sequences of the gene of interest (108). These cassettes are frequently generated by $\mathrm{PCR}$, using primers containing both bordering regions of the target gene and part of the selectable marker gene, and subsequently used to transform yeast cells through various transformation protocols, but usually by the lithium acetate TRAFO method (109). There has been widespread use of gene disruption cassettes generated by PCR $(110,111)$, since very short sequences of yeast DNA flanking the marker gene are sufficient for efficient integration into the Sacharomyces cerevisiae genome by homologous recombination (112). 
Therefore, it is possible to screen a relatively small number of the transformants growing on the selection media (usually by PCR) and confirm correct integration of the cassette. When recombination efficiency is very low but cells are under selection pressure, cassettes are often integrated in the wrong locus, giving rise to a large number of false positives (cells that are able to grow on the selection media, but not actual disruptants), and the number of true positives may be lower than 1 in a 100. It then becomes necessary to perform a secondary screen, which is only possible when deletion of the gene of interest results in a readily identifiable phenotype. Evidence of the low efficiency of $T$. delbrueckii homologous recombination emerged when disruption of the TdMAL11 gene was attempted (95); however, in that case it was possible to screen the transformants through phenotypic analysis, since TdMAL11 null mutants exhibit deficient growth on medium containing maltose as the sole carbon source. However, it was not possible to use the same strategy to disrupt LGT1, the first gene identified as coding for a hexose transporter in T. delbrueckii, since there was evidence that other hexose transporters exist in this yeast (50). Therefore, we could not screen for potential T. delbrueckii LGT1 disruptants by searching for a clear-cut phenotype, because loss of LGT1 might be compensated by the activities of other genes and was thus not expected to impair glucose growth capacity. Therefore, using the conventional method of transforming a PCR-amplified disruption cassette with a short flanking homology (SFH-PCR) (113), we were unable to generate $\Delta l g t 1$ mutants. Our strategy was thus first to obtain a TdLGT1-targeting cassette harboring longer homology arms, and then to attempt further optimization of the yield of LGT1 disruption, by testing how different parameters inherent to the lithium acetate method described by (109) contributed to the transformation efficiency (114). We constructed a cassette with longer flanking regions by inserting a marker-resistance module into the core of the LGT1 gene, and then used this construction as a template for PCR amplification of a TdLGT1 long-flanking homology disruption cassette (figure 2). Then, to further improve the yield of LGT1 disruption, we reformulated some parameters of the transformation method. Mainly, after heat shock, cells were pelleted and resuspended in rich medium supplemented with low concentrations of geneticin (100 $\left.\mathrm{mg} \mathrm{mL}^{-1}\right)$ and incubated overnight (instead of the usual 4-h recovery time). Finally, cells were plated onto selective YPD plates supplemented with higher concentrations of geneticin $\left(300 \mathrm{mg} \mathrm{mL}^{-1}\right)$, to select against false positives, and incubated for up to 4 days.

Integration efficiency using this strategy was extremely high when compared with the conventional method (no disruptants from using the conventional method and 12/16 using this improved method). We thus concluded that two important modifications were the most relevant for our global strategy: the size of the disruption cassette and the new recovery period of cells during the transformation protocol. As a result, this method demonstrated to be a valuable alternative to the conventional PCR-based gene disruption for the yeast $T$. delbrueckii. This methodology could also be advantageously applied to other non-conventional yeasts, where correct gene disruption with the commonly used short flanking homology cassettes is frequently very low. 


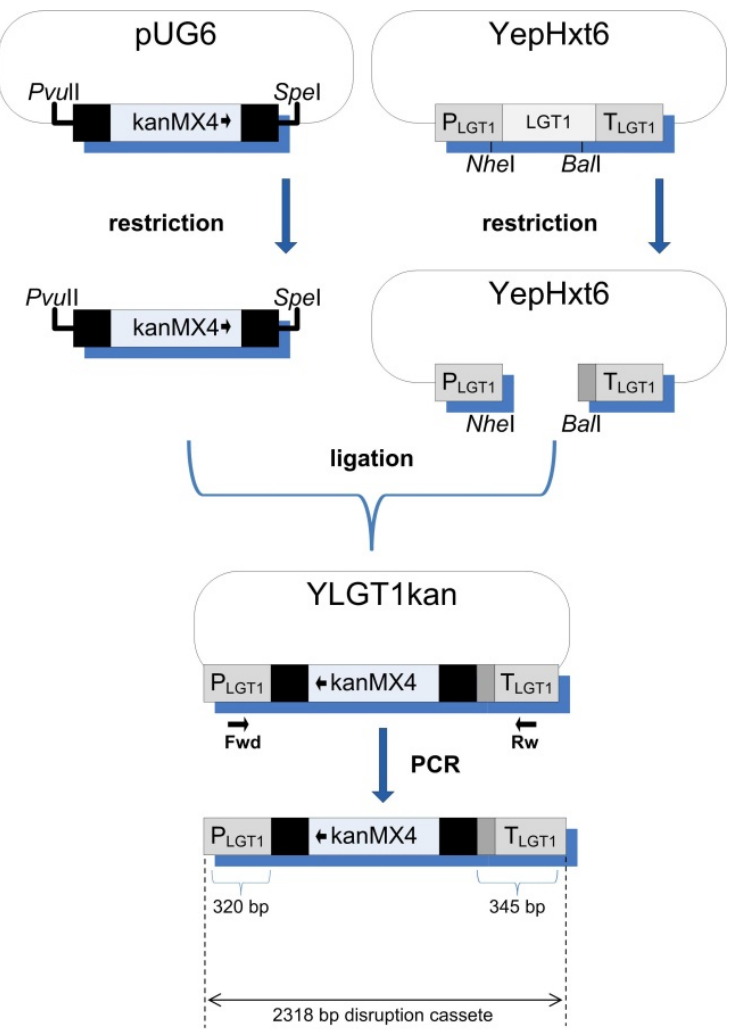

Figure 2. Schematic illustration of the construction of Torulaspora delbrueckii LGT1 disruption cassete. pUG6 plasmid was digested with PvuII and SpeI to release de KanMX4 module, which confers resistance to geneticin (left side of the scheme). In parallel YepHxt6 plasmid (which contains LGT1 ORF and part of the gene promoter and terminator regions) was restricted with NheI and BalI, removing nearly the entire ORF (right side of the scheme). Afterward the PvuII-loxP-KanMX-loxP-SpeI released from pUG6 was cloned into BalI/NheI restricted YepHxt6, creating YLGT1kan plasmid, the template to generate the $L G T 1$ disruption cassette. Using specific primers to $L G T 1$ promoter and terminator regions, the disruption cassette ( $2318 \mathrm{bp}$ ) containing the marker module flanked by 320 and $345 \mathrm{bp}$ ( $5^{\prime}$ and $3^{\prime}$ sides, respectively) LGT1 homologous regions was generated by PCR. This cassette was used to transform T. delbrueckii with a modified LiAc transformation protocol (described in the text). PLGT1 and TLGT1 are the promoter and terminator regions, respectively, of T. delbrueckii LGT1 gene. Restriction enzyme sites and the sizes of the DNA fragments are shown. Arrows at either end of the module represent the oligonucleotides used for PCR.

\section{Molecular characterization of Torulaspora delbrueckii strains}

Before we can exploit the potential of Torulaspora delbruecckii in industrial processess, we must be able to identify it and distinguish between strains, using reliable techniques. The accessibility of typing techniques that enable a rapid and accurate differentiation at the strain level is imperative for both wine and baker's yeast users and producers, to assure that 
the commercialized yeast corresponds to the strain selected originally. Thus, developing practical typing techniques that enable discrimination between $T$. delbrueckii strains is an essential tool for its implementation in the baking and wine industries.

In order to determine the suitability of mitochondrial DNA restriction analysis for $T$. delbrueckii strain differentiation, we selected additional autochthonous yeast strains from the yeast flora present on the home-made corn and rye bread doughs in the northern area of Portugal (unpublished results from our laboratory). We first screened 134 isolates by restriction pattern analysis of both PCR-amplified 5.8S rRNA gene and internally transcribed spacers ITS1 and ITS2, as previously described (115), selecting only T. delbrueckii species. The total length of the ITS1-5.8S-ITS2 regions of the 5.8S rRNA gene is identical for all T. delbrueckii strains, and for that reason this method cannot discriminate at the strain level $(45,115-117)$. Three isolates $(45 \mathrm{~A}, 45 \mathrm{D}$ and $62 \mathrm{C})$ were selected and placed in the CBMA yeast culture collection, Department of Biology, University of Minho, Braga-Portugal. To discriminate between $T$. delbrueckii strains, both mitochondrial DNA restriction fragment length polymorphism and pulsed-field gel electrophoresis (PFGE) were applied to the three selected isolates, to T. delbrueckii PYCC 5321 and PYCC 5323, and to type strain ISA1082 (Portuguese Yeast Culture Collection, Institute Gulbenkian de Ciência, Oeiras -Portugal) for a comparative pattern.

Mitochondrial DNA restriction fragment length polymorphism (mtRFLP) analysis has been widely applied to the characterization of reference and commercial Saccharomyces cerevisiae wine yeast strains (118-123), as well as strains belonging to other species $(116,124)$. Not all the enzymes used in this method detect the same degree of polymorphisms, which depend greatly on the species. mtRFLP using Hinfl is associated with the detection of a high polymorphism and is a widely used genetic marker to distinguish $S$. cerevisiae wine strains $(118,122,125,126)$. On the other hand, GC clusters of the mitochondrial genome are the main source of the polymorphisms, and a large portion of these contains restriction sites for Haelll.

For mtRFLP, DNA was isolated from yeast cells grown in YPD and digested with HinfI or HaeIII restriction enzymes. Restriction fragments were separated in horizontal agarose gels (figure 3). mtRFLP's of the six strains using Hinfl or Haelll resulted in two distinct profiles, with slight variability. The major difference was found in the upper bands, where the resolution is better (figure 3 arrows). Apart from these bands, the pattern of the profiles provided by each enzyme is identical, indicating that these strains are genetically very closely related. Restriction with $\operatorname{Hinfl}$ resulted in one profile including $T$. delbrueckii ISA1082 (type strain), T. delbrueckii PYCC 5321, 45A and 45D, and in another profile including T. delbrueckii PYCC 5323 and 62C strains (Fig.3A). Restriction analysis with HaeIII resulted in a profile including T. delbrueckii PYCC 5321 and 45A, and a second profile that includes T. delbrueckii ISA1082, T. delbrueckii PYCC 5323, 45D, and $62 \mathrm{C}$ strains (figure $3 \mathrm{~B}$ ). This method is therefore not suitable to discriminate between $T$. delbrueckii strains. 
A

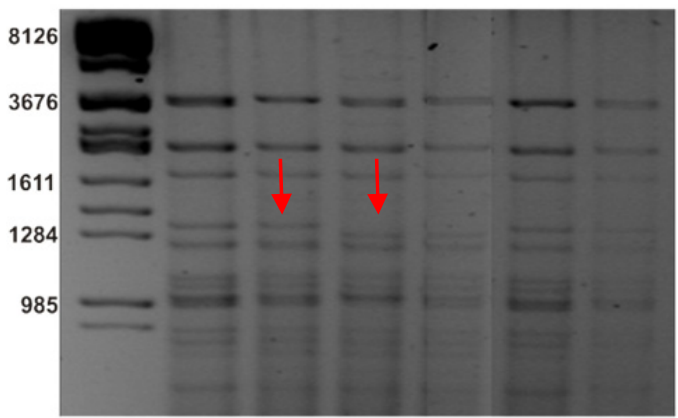

B

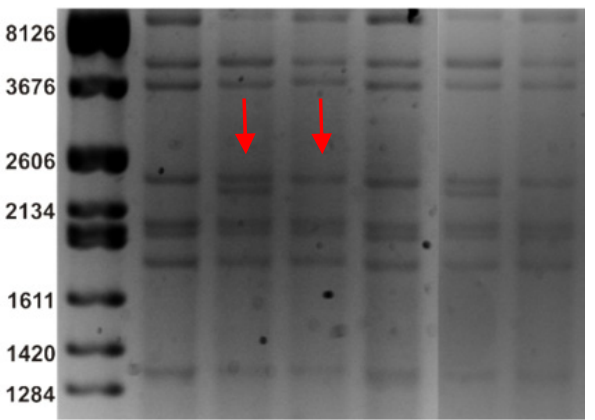

Figure 3. Mitochondrial DNA restriction profiles of T. delbrueckii strains obtained with the (A) Hinfl and (B) HaeIII restriction endonucleases in 1.5\% agarose gel (unpublished results from our laboratory). Lane 1 - Molecular Marker Lambda DNA/Eco47I (AvaII) from Fermentas; Lane 2 - T. delbrueckii ISA1082 (reference strain); Lane 3 - T. delbrueckii PYCC 5321; Lane 4 - T. delbrueckii PYCC 5323; Lane 5 - 62C; Lane 6 - 45A; Lane 7 - 45D. Arrows indicate main differences between profiles I and II. Yeast cells were cultivated in $1 \mathrm{ml}$ YPD (1\% yeast extract, $2 \%$ peptone, $2 \%$ glucose) for $24 \mathrm{~h}$ at $30{ }^{\circ} \mathrm{C}$ and 160 r.p.m and DNA isolation was performed as previously described (126). Digestion was carried out with Hinfl or HaeIII restriction enzymes overnight at $37^{\circ} \mathrm{C}$, in a final volume of $20 \mu \mathrm{l}$ as previously described (123). Restriction fragments were separated in horizontal 1.5\% agarose gels run in $0.5 \mathrm{X}$ TBE buffer at $60 \mathrm{~V}$ for six hours and visualized in a UV transilluminator (Eagleeye II Image Acquisition System, Stratagene, La Jolla, CA) after ethidium bromide staining.

Karyotype analysis is a highly efficient technique to differentiate strains of S. cerevisiae, and was applied by numerous authors to characterize reference and commercial yeasts belonging to different species $(118,120,122,123,127)$. The electrophoretic karyotypes of the strains under study were therefore also compared. Intact DNA for pulsed field gel electrophoresis (PFGE) was prepared in plugs as previously described (128) and PFGE was run in a CHEF-DRII Chiller System (Bio-Rad, Hercules, CA). Under the conditions used, six chromosome bands were detected in all the strains, which is in agreement with previous studies indicating $T$. delbrueckii has six chromosomes (129). PFGE gel electrophoresis revealed that the chromosomal DNA banding profiles of the strains differ substantially (figure 4), and six different karyotypes could be defined on the basis of the size of putative chromosomes, thereby allowing the discrimination of 4 strains that were not indistinguishable by mtRFLP.

The different karyotypes of the six strains are consistent with their different phenotypes. Indeed, T. delbrueckii PYCC 5321, PYCC 5323, and T. delbrueckii ISA1082 (type strain) have already been established as different strains (4) and several physiological and biochemical studies of the other three isolates indicated they also correspond to different strains (our unpublished results). Contrary to reports of molecular typing of other yeasts (123), where both methods allowed discriminating strains in a similar manner, our results show that karyotyping analysis displayed a much higher discriminative power than mtRFLP for $T$. delbrueckii strains. A reasonable explanation for this difference may be the need for higher 
stability of an intact mitochondrial genome in this species than in S. cerevisiae. For instance, we have already shown that the relative contribution of respiration to sugar catabolism is higher in T. delbrueckii than in S. cerevisiae (7). Although mitochondrial genomes contain a very similar set of genes common to all organisms, mtDNA molecules among species are extremely variable in size and organization (130). Furthermore, the stability of the mitochondrial genome can be evaluated by the ability to form petite mutants. S. cerevisiae spontaneously produces these mutants, which are deficient in the capacity to respire aerobically. The petite phenotype is correlated with gross alterations and extensive deletions or loss of mtDNA $(131,132)$. On the contrary, T. delbrueckii is a petite-negative species, as it doesn't have the ability to form these respiratory mutants even after prolonged treatment with ethidium bromide (133-135). The high resolutive capability of the CHEF technique allowed us to differentiate between strains isolated from the same environment and that could not be distinguished by mtRFLP. These results underline this technique as a powerful tool for T. delbrueckii strain differentiation, although there are some factors that limit its applicability, since it is complex and time-consuming and not suitable as a routine technique for strain identification.

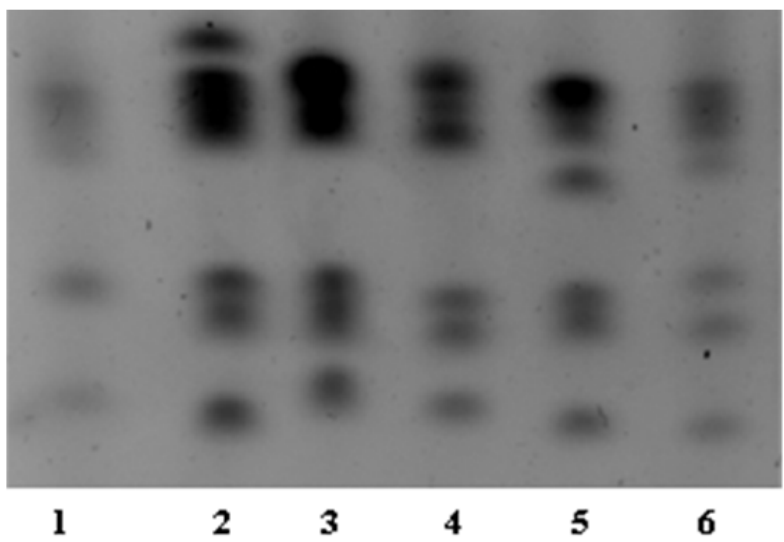

Figure 4. Electrophoretic karyotype comparison of T. delbrueckii strains (unpublished results from our laboratory). Lane 1- T. delbrueckii ISA1082 (reference strain): Lane 2 - T. delbrueckii PYCC 5321; Lane 3 - T. delbrueckii PYCC 5323; Lane 4 - 62C; Lane 5 - 45A. Lane 6 - 45D. DNA for pulsed field gel electrophoresis (PFGE) was prepared in plugs as previously described (128). PFGE was run in a CHEF-DRII Chiller System (Bio-Rad, Hercules, CA). PFGE gels were run in 0.5\% Tris borate-EDTA buffer at $12{ }^{\circ} \mathrm{C}$ with an angle of $120^{\circ}$ with the following voltage and switch times: $480 \mathrm{~s} \rightarrow 900 \mathrm{~s}, 3 \mathrm{v} / \mathrm{cm}$ for 10 hours; $240 \mathrm{~s} \rightarrow 480 \mathrm{~s}, 3 \mathrm{v} / \mathrm{cm}$ for 15 hours; $120 \mathrm{~s} \rightarrow 240 \mathrm{~s}, 3 \mathrm{v} / \mathrm{cm}$ for 15 hours; $90 \mathrm{~s}, 6 \mathrm{v} / \mathrm{cm}$ for 10 hours and $60 \mathrm{~s}, 6 \mathrm{v} / \mathrm{cm}$ for 5 hours. Thereafter, gels were stained with $0.8 \%$ ethidium bromide for $45 \mathrm{~min}$ and de-stained for $20 \mathrm{~min}$. Gels were visualized under UV light and analyzed using the EagleEye II Image Acquisition System (Stratagene, La Jolla, CA).

In summary, the karyotyping profiles and RFLP's of mitochondrial DNA of the T. delbrueckii strains PYCC 5321 and PYCC 5323 were clearly different. These data corroborate and complement the results obtained in the past by the classical biochemical methodology (6), 
representing an update to the understanding of $T$. delbrueckii populations present in bread doughs. Furthermore, the availability of functional typing tools that enable differentiation at the strain level is extremely important to the bread and wine industries, to assure traceability of the selected strains.

\section{Conclusion}

The biotechnological interest in Torulaspora delbrueckii has increased in recent years due to its particularly high freezing and osmotic tolerance $(4,5,46)$. These features made this yeast species a candidate of potential value for the baking industry. However, the existing knowledge on this yeast is still far from the vast knowledge on the traditional baker's yeast Saccharomyces cerevisiae. Therefore, studies have been developed to gain insight into the physiology, biochemistry, and molecular genetics of T. delbrueckii.

While two of the most important traits for large-scale baker's yeast production are its growth rate and biomass yield on sucrose, its leavening ability depends mainly on its capacity to ferment maltose. The pattern of sugar utilization and regulation also determines the yeast capacity to rapidly adapt when changing from sucrose-rich growth medium to the dough. Physiological and biochemical studies of T. delbrueckii in batch cultures with the sugars present in molasses and in bread dough, both alone and in mixtures, showed that $T$. delbrueckii behaves very similarly to $S$. cerevisiae with respect to sugar utilization and regulation patterns. However, this yeast modulates respiratory metabolism under aerobic conditions more efficiently, an asset for large-scale production of the yeast. Furthermore, comparative analysis of specific sugar consumption rates and transport capacities suggested that it is the transport step that limits both glucose and maltose metabolism.

So far, only one glucose transporter has been identified in T. delbrueckii, the low-affinity glucose transporter LGT1 (50). Southern blot analysis of the T. delbrueckii genome revealed the existence of several genes with high similarity to LGT1, suggesting there are several hexose transporters in this yeast, which hampered disruption of the LGT1 gene. The existence of several hexose transporters had first been suggested by the isolation of several plasmids from a genomic library of this strain that could complement the glucose growth defect of the $S$. cerevisiae hexose transport-null mutant (50). Despite the phylogenetic closeness of T. delbrueckii and S. cerevisiae, the differences observed between the two species show that the behavior or even the methods that can be applied to the former yeast cannot always be inferred from those of $S$. cerevisiae. For instance, when we attempted to disrupt the T. delbrueckii LGT1 gene, the current methods used for S. cerevisiae were not suitable, and an optimized disruption method had to be developed.

In modern food technology, traceability is a crucial requirement, and thus establishing a rapid method to discriminate between $T$. delbrueckii strains is of upmost relevance. This technique would enable correct identification of the inoculated strain from the remaining yeast flora present in the bread dough. In the last years, several methodologies of typing based on DNA patterns have been developed which allowed discriminating closely related 
yeast strains. In this chapter, two different genetic fingerprinting techniques (karyotype analysis and mtDNA restriction analysis) were presented for detailed genotyping of $T$. delbrueckii strains. Mitochondrial DNA restriction analysis was not a good technique to differentiate among T. delbrueckii strains isolated from the same ecosystem and genetically very closely related. Chromosome separation by pulsed-field electrophoresis revealed considerable variability in the chromosomal constitution of the strains studied, and turned out to be a useful method to discriminate among T. delbrueckii strains. However, this method of chromosome karyotyping may be too complex, laborious, and time-consuming for the analysis of numerous yeast isolates, in contrast with mtDNA restriction analysis.

Nowadays, yeast strains used in bread industry are involved in large-scale processes and hence are exposed to more extreme stress conditions. On the other hand, development of new products and more versatile processes also require yeast strains with new traits. This chapter aimed to highlight some of these emergent problems/needs in the wine and bread-making industries, including selecting, characterizing, and constructing resistant yeast strains, and strains with important qualities for application in the baking and wine industries, as is the case of some studied strains of T. delbruekii.

Despite the accomplishments reported in this chapter, many important questions remain to be answered regarding sugar transporters and freezing resistance in T. delbrueckii. How many hexose transporters are present in T. delbrueckii? What are their affinities and regulation? Is T. delbrueckii similar to K. lactis, as speculated by Alves-Araújo (50), based on comparison of sequencing data and regulatory studies of LGT1 expression? Or is this yeast more comparable to $S$. cerevisiae as is suggested by their similar sugar utilizations patterns (7)? Evidently, it would be important to continue the characterization of T. delbrueckii strains, as their biotechnological potential has already been established $(5,7,46)$. It is clear that answers to these questions may only arise from future studies. Characterization of $T$. delbrueckii at the different levels will narrow the gap towards its industrial exploitation and increase knowledge on the so-called non-conventional yeast species.

\section{Author details}

Andreia Pacheco, Susana Chaves and Judite Almeida

Molecular and Environmental Research Centre (CBMA)/Department of Biology,

University of Minho, Braga, Portugal

Júlia Santos and Cecília Leão

Life and Health Sciences Research Institute (ICVS), School of Health Sciences, University of Minho, Braga, Portugal

ICVS/3B's - PT Government Associate Laboratory, Braga/Guimarães, Portugal

Maria João Sousa

Corresponding Author

Molecular and Environmental Research Centre (CBMA)/Department of Biology,

University of Minho, Braga, Portugal 


\section{References}

[1] Rainieri S, Pretorius IS. Selection and improvement of wine yeasts. Ann Microbiol. 2000;50(1):15-31.

[2] Schuller D, Casal M. The use of genetically modified Saccharomyces cerevisiae strains in the wine industry. Applied microbiology and biotechnology. 2005;68(3):292-304.

[3] Randez-Gil F AJ, Codón A, Rincón AM, Estruch F \& Prieto JA. Baker's yeast: challenges and future aspects. Functional Genetics of Industrial Yeasts. de Winde JH ed2003.

[4] Almeida MJ, Pais C. Leavening ability and freeze tolerance of yeasts isolated from traditional corn and rye bread doughs. Applied and environmental microbiology. 1996;62(12):4401-4.

[5] Alves-Araujo C, Almeida MJ, Sousa MJ, Leão C. Freeze tolerance of the yeast Torulaspora delbrueckii: cellular and biochemical basis. FEMS microbiology letters. 2004;240(1):7-14.

[6] Almeida MJ, Pais C. Characterization of yeast population from traditional corn and rye bread doughs. Letters in applied microbiology. 1996;23:154-8.

[7] Alves-Araujo C, Pacheco A, Almeida MJ, Spencer-Martins I, Leao C, Sousa MJ. Sugar utilization patterns and respiro-fermentative metabolism in the baker's yeast Torulaspora delbrueckii. Microbiology. 2007;153(Pt 3):898-904.

[8] Mercado L, Dalcero A, Masuelli R, Combina M. Diversity of Saccharomyces strains on grapes and winery surfaces: analysis of their contribution to fermentative flora of Malbec wine from Mendoza (Argentina) during two consecutive years. Food microbiology. 2007;24(4):403-12.

[9] Mortimer R, Polsinelli M. On the origins of wine yeast. Research in microbiology. 1999;150(3):199-204.

[10] Lafon-Lafourcade S, Geneix C, Ribereau-Gayon P. Inhibition of alcoholic fermentation of grape must by Fatty acids produced by yeasts and their elimination by yeast ghosts. Applied and environmental microbiology. 1984;47(6):1246-9.

[11] Kunkee RE, Goswell RW. Table wines. Rose AH, editor: Acad. Press. Inc. (London); 1977.

[12] Pretorius IS. Tailoring wine yeast for the new millennium: novel approaches to the ancient art of winemaking. Yeast. 2000;16(8):675-729.

[13] Esteve-Zarzoso B, Manzanares P, Ramon D, Querol A. The role of non-Saccharomyces yeasts in industrial winemaking. International microbiology : the official journal of the Spanish Society for Microbiology. 1998;1(2):143-8.

[14] Bisson LF. Biotechnology of wine yeast. Food Biotechnol. 2004;18(1):63-96.

[15] Rainieri S, Zambonelli C, Tini V, Castellari L, Giudici P. The enological traits of thermotolerant Saccharomyces strains. Am J Enol Viticult. 1998;49(3):319-24.

[16] Sousa MJ, Teixeira JA, Mota M. Malo-alcoholic fermentation: the influence of operating conditions on the kinetics of deacidification. Journal of Wine Reseach. 1991;2:115-24.

[17] Sousa MJ, Teixeira JA, M. M. Must deacidification with na induced flocculant yeast strain of S. pombe. Appl Microbiol Biotechnol 1993;39:189-93. 
[18] Taillandier P, Riba JP, Strehaiano P. Malate utilization by S. pombe Biotechnology Letters. 1988;10:469-72.

[19] Ciani M, Maccarelli F. Oenological properties of non-Saccharomyces yeasts associated with wine-making. World J Microb Biot. 1998;14(2):199-203.

[20] Bisson LF, Waterhouse AL, Ebeler SE, Walker MA, Lapsley JT. The present and future of the international wine industry. Nature. 2002;418(6898):696-9.

[21] Mills DA, Johannsen EA, Cocolin L. Yeast diversity and persistence in botrytis-affected wine fermentations. Applied and environmental microbiology. 2002;68(10):4884-93.

[22] Rankine BC, Lloyd B. Quantitative assessment of 9 dominance of added yeast in wine fermentations. J Sci Food Agric. 1963;14:793-8.

[23] Kunkee RE, Amerine MA. Yeasts in winemaking: Acad. Press. Inc. (London),; 1970. 5-72 p.

[24] Sommer P, Stolpe E, Kramp B, Heinemeyer J. Dried Starter Cultures of NonSaccharomyces Yeasts for Alcoholic Fermentation: Impact of Kluyveromyces thermotolerans or Torulaspora delbrueckii with Saccharomyces cerevisiae on Aroma and Flavor Development in Wine. ASEV 54th Annual Meeting. 2003:83.

[25] Herraiz T, Reglero, G., Herraiz, M., Martin-Alvarez, P.J., Cabezudo, M. The influence of the yeast and type of culture on the volatile composition of wine fermented without sulphur dioxide. Am J Enol Viticult. 1990;41:313-8.

[26] Ciani M, Picciotti, G. The growth kinetics and fermentation behaviour of some nonSaccharomyces yeasts associated with wine-making. Biotechnology Letters 1995;17:1247-50.

[27] Ciani M, Ferraro L. Combined use of immobilized Candida stellata cells and Saccharomyces cerevisiae to improve the quality of wines. Journal of applied microbiology. 1998;85(2):247-54.

[28] Romano P, Fiore C, Paraggio M, Caruso M, Capece A. Function of yeast species and strains in wine flavour. International journal of food microbiology. 2003;86(1-2):169-80.

[29] Fleet GH. Yeast interactions and wine flavour. International journal of food microbiology. 2003;86(1-2):11-22.

[30] Martinez J, Toledano, F., Millan, C. Development of alcoholic fermentation in nonsterile musts from Pedro Ximenez grapes inoculated with pure cultures of selected yeasts. Food microbiology. 1990;7:217-25.

[31] Bely M, Stoeckle P, Masneuf-Pomarede I, Dubourdieu D. Impact of mixed Torulaspora delbrueckii-Saccharomyces cerevisiae culture on high-sugar fermentation. International journal of food microbiology. 2008;122(3):312-20.

[32] Ciani M, Beco L, Comitini F. Fermentation behaviour and metabolic interactions of multistarter wine yeast fermentations. International journal of food microbiology. 2006;108(2):239-45.

[33] Panjai L, Ongthip K, Chomsri N. Complex fruit wine produced from dual culture fermentation of pineapple juice with torulaspora delbrueckii and saccharomyces cerevisiae. International Conference on the Role of Universities in Hands-On Education; Rajamangala University of Technology Lanna, Chiang-Mai, Thailand 2009. 
[34] Hernandez-Lopez MJ, Randez-Gil F, Prieto JA. Hog1 mitogen-activated protein kinase plays conserved and distinct roles in the osmotolerant yeast Torulaspora delbrueckii. Eukaryotic cell. 2006;5(8):1410-9.

[35] Santos J, Sousa MJ, Cardoso H, Inacio J, Silva S, Spencer-Martins I, et al. Ethanol tolerance of sugar transport, and the rectification of stuck wine fermentations. Microbiology. 2008;154(Pt 2):422-30.

[36] Attfield PV. Stress tolerance: the key to effective strains of industrial baker's yeast. Nature biotechnology. 1997;15(13):1351-7.

[37] Randez-Gil F, Sanz P, Prieto JA. Engineering baker's yeast: room for improvement. Trends Biotechnol. 1999;17(6):237-44.

[38] Benitez B, Gasent-Ramirez, J. M., Castrejon, F. \& Codon, A. C. Development of new strains for the food industry. Biotechnol Prog. 1996;12:149-63.

[39] Sinda E., Parkkinen E, editors. Problems with Molasses in the Yeast Industry.: Helsinki: Kauppakirjapainooy.; 1979.

[40] Vaughan-Martini A, Martini A. Saccharomyces Meyen ex Reess In: Kurtzman CP, Fell JW, editors. The Yeasts, a Taxonomic Study. 4 ed. Amsterdam: Elsevier; 1998.

[41] de Winde JH. Functional Genetics of Industrial Yeasts.2003.

[42] Mormeneo S, Sentandreu R. Regulation of invertase synthesis by glucose in Saccharomyces cerevisiae. Journal of bacteriology. 1982;152(1):14-8.

[43] Attfield PV, Kletsas S. Hyperosmotic stress response by strains of bakers' yeasts in high sugar concentration medium. Lett Appl Microbiol. 2000;31(4):323-7.

[44] Hernandez-Lopez MJ, Pallotti C, Andreu P, Aguilera J, Prieto JA, Randez-Gil F. Characterization of a Torulaspora delbrueckii diploid strain with optimized performance in sweet and frozen sweet dough. International journal of food microbiology. 2007;116(1):103-10.

[45] Valmorri S, Tofalo R, Settanni L, Corsetti A, Suzzi G. Yeast microbiota associated with spontaneous sourdough fermentations in the production of traditional wheat sourdough breads of the Abruzzo region (Italy). Antonie van Leeuwenhoek. 2010;97(2):119-29.

[46] Hernandez-Lopez MJ, Prieto JA, Randez-Gil F. Osmotolerance and leavening ability in sweet and frozen sweet dough. Comparative analysis between Torulaspora delbrueckii and Saccharomyces cerevisiae baker's yeast strains. Antonie van Leeuwenhoek. 2003;84(2):125-34.

[47] Winde J. Functional Genetics of Industrial Yeasts. Hohman S, editor: Springer; 2003. 367 p.

[48] Kurtzman CP. Torulaspora Lindner. The Yeasts: A Taxonomic Study. 4th ed: Elsevier, Amsterdam, the Netherlands; 1998.

[49] Sasaki T, Ohshima Y. Induction and Characterization of Artificial Diploids from the Haploid Yeast Torulaspora delbrueckii. Appl Environ Microbiol. 1987;53(7):1504-11.

[50] Alves-Araújo C, Hernandez-Lopez MJ, Prieto JA, Randez-Gil F, Sousa MJ. Isolation and characterization of the LGT1 gene encoding a low-affinity glucose transporter from Torulaspora delbrueckii. Yeast. 2005;22(3):165-75. 
[51] Diderich JA, Schepper M, van Hoek P, Luttik MA, van Dijken JP, Pronk JT, et al. Glucose uptake kinetics and transcription of HXT genes in chemostat cultures of Saccharomyces cerevisiae. The Journal of biological chemistry. 1999;274(22):15350-9.

[52] Hernandez-Lopez MJ, Prieto JA, Randez-Gil F. Isolation and characterization of the carbon catabolite-derepressing protein kinase Snf1 from the stress tolerant yeast Torulaspora delbrueckii. Yeast. 2010;27(12):1061-9.

[53] Needleman R. Control of maltase synthesis in yeast. Molecular microbiology. 1991;5(9):2079-84.

[54] Gancedo JM. Yeast carbon catabolite repression. Microbiology and molecular biology reviews : MMBR. 1998;62(2):334-61.

[55] Baldwin SA, Henderson PJ. Homologies between sugar transporters from eukaryotes and prokaryotes. Annu Rev Physiol. 1989;51:459-71.

[56] Henderson PJ, Maiden MC. Homologous sugar transport proteins in Escherichia coli and their relatives in both prokaryotes and eukaryotes. Philos Trans R Soc Lond B Biol Sci. 1990;326(1236):391-410.

[57] Maiden MC, Davis EO, Baldwin SA, Moore DC, Henderson PJ. Mammalian and bacterial sugar transport proteins are homologous. Nature. 1987;325(6105):641-3.

[58] Vardy E, Arkin IT, Gottschalk KE, Kaback HR, Schuldiner S. Structural conservation in the major facilitator superfamily as revealed by comparative modeling. Protein Sci. 2004;13(7):1832-40.

[59] Pao SS, Paulsen IT, Saier MH, Jr. Major facilitator superfamily. Microbiol Mol Biol Rev. 1998;62(1):1-34.

[60] Kruckeberg AL. The hexose transporter family of Saccharomyces cerevisiae. Arch Microbiol. 1996;166(5):283-92.

[61] Saier MH, Jr. Families of transmembrane sugar transport proteins. Mol Microbiol. 2000;35(4):699-710.

[62] Lodish H, Baltimore, D., Berk, A. Molecular Cell Biology. 3 ed. books SA, editor. New York: W.H. Freeman \& Co.; 1995.

[63] Postma E, Kuiper A, Tomasouw WF, Scheffers WA, van Dijken JP. Competition for glucose between the yeasts Saccharomyces cerevisiae and Candida utilis. Appl Environ Microbiol. 1989;55(12):3214-20.

[64] van Urk H, Postma E, Scheffers WA, van Dijken JP. Glucose transport in crabtreepositive and crabtree-negative yeasts. J Gen Microbiol. 1989;135(9):2399-406.

[65] Boles E, Hollenberg CP. The molecular genetics of hexose transport in yeasts. FEMS Microbiol Rev. 1997;21(1):85-111.

[66] Van Belle D, Andre B. A genomic view of yeast membrane transporters. Curr Opin Cell Biol. 2001;13(4):389-98.

[67] Reifenberger E, Freidel K, Ciriacy M. Identification of novel HXT genes in Saccharomyces cerevisiae reveals the impact of individual hexose transporters on glycolytic flux. Mol Microbiol. 1995;16(1):157-67.

[68] Nehlin JO, Carlberg M, Ronne H. Yeast galactose permease is related to yeast and mammalian glucose transporters. Gene. 1989;85(2):313-9. 
[69] Szkutnicka K, Tschopp JF, Andrews L, Cirillo VP. Sequence and structure of the yeast galactose transporter. J Bacteriol. 1989;171(8):4486-93.

[70] Ozcan S, Johnston M. Function and regulation of yeast hexose transporters. Microbiology and molecular biology reviews : MMBR. 1999;63(3):554-69.

[71] Wieczorke R, Krampe S, Weierstall T, Freidel K, Hollenberg CP, Boles E. Concurrent knock-out of at least 20 transporter genes is required to block uptake of hexoses in Saccharomyces cerevisiae. FEBS letters. 1999;464(3):123-8.

[72] Reifenberger E, Boles E, Ciriacy M. Kinetic characterization of individual hexose transporters of Saccharomyces cerevisiae and their relation to the triggering mechanisms of glucose repression. Eur J Biochem. 1997;245(2):324-33.

[73] Meijer MM, Boonstra J, Verkleij AJ, Verrips CT. Glucose repression in Saccharomyces cerevisiae is related to the glucose concentration rather than the glucose flux. J Biol Chem. 1998;273(37):24102-7.

[74] De Hertogh B, Hancy F, Goffeau A, Baret PV. Emergence of species-specific transporters during evolution of the hemiascomycete phylum. Genetics. 2006;172(2):771-81.

[75] Varma A, Singh BB, Karnani N, Lichtenberg-Frate H, Hofer M, Magee BB, et al. Molecular cloning and functional characterisation of a glucose transporter, CaHGT1, of Candida albicans. FEMS Microbiol Lett. 2000;182(1):15-21.

[76] Fan J, Chaturvedi V, Shen SH. Identification and phylogenetic analysis of a glucose transporter gene family from the human pathogenic yeast Candida albicans. J Mol Evol. 2002;55(3):336-46.

[77] Arnaud MB, Costanzo MC, Skrzypek MS, Shah P, Binkley G, Lane C, et al. Sequence resources at the Candida Genome Database. Nucleic Acids Res. 2007;35(Database issue):D452-6.

[78] Heiland S, Radovanovic N, Hofer M, Winderickx J, Lichtenberg H. Multiple hexose transporters of Schizosaccharomyces pombe. J Bacteriol. 2000;182(8):2153-62.

[79] Weierstall T, Hollenberg CP, Boles E. Cloning and characterization of three genes (SUT1-3) encoding glucose transporters of the yeast Pichia stipitis. Mol Microbiol. 1999;31(3):871-83.

[80] Jeffries TW, Grigoriev IV, Grimwood J, Laplaza JM, Aerts A, Salamov A, et al. Genome sequence of the lignocellulose-bioconverting and xylose-fermenting yeast Pichia stipitis. Nat Biotechnol. 2007;25(3):319-26.

[81] Stasyk OG, Maidan MM, Stasyk OV, Van Dijck P, Thevelein JM, Sibirny AA. Identification of hexose transporter-like sensor HXS1 and functional hexose transporter HXT1 in the methylotrophic yeast Hansenula polymorpha. Eukaryotic cell. 2008;7(4):73546.

[82] Wei H, Vienken K, Weber R, Bunting S, Requena N, Fischer R. A putative high affinity hexose transporter, hxtA, of Aspergillus nidulans is induced in vegetative hyphae upon starvation and in ascogenous hyphae during cleistothecium formation. Fungal genetics and biology : FG \& B. 2004;41(2):148-56. 
[83] Gonçalves P, Rodrigues de Sousa H, Spencer-Martins I. FSY1, a novel gene encoding a specific fructose $/ \mathrm{H}(+)$ symporter in the type strain of Saccharomyces carlsbergensis. J Bacteriol. 2000;182(19):5628-30.

[84] Pina C, Goncalves P, Prista C, Loureiro-Dias MC. Ffz1, a new transporter specific for fructose from Zygosaccharomyces bailii. Microbiology. 2004;150(Pt 7):2429-33.

[85] Attfield AV, Bell PJ. Genetics and classical genetic manipulations of industrial yeasts2003. 17-55 p.

[86] Mortimer RK, Contopoulou CR, King JS. Genetic and physical maps of Saccharomyces cerevisiae, Edition 11. Yeast. 1992;8(10):817-902.

[87] Volckaert G, Voet M, Robben J. Sequence analysis of a near-subtelomeric $35.4 \mathrm{~kb}$ DNA segment on the right arm of chromosome VII from Saccharomyces cerevisiae carrying the MAL1 locus reveals 15 complete open reading frames, including ZUO1, BGL2 and BIO2 genes and an ABC transporter gene. Yeast. 1997;13(3):251-9.

[88] Day RE, Higgins VJ, Rogers PJ, Dawes IW. Characterization of the putative maltose transporters encoded by YDL247w and YJR160c. Yeast. 2002;19(12):1015-27.

[89] Han EK, Cotty F, Sottas C, Jiang H, Michels CA. Characterization of AGT1 encoding a general alpha-glucoside transporter from Saccharomyces. Molecular microbiology. 1995;17(6):1093-107.

[90] Day RE, Rogers PJ, Dawes IW, Higgins VJ. Molecular analysis of maltotriose transport and utilization by Saccharomyces cerevisiae. Applied and environmental microbiology. 2002;68(11):5326-35.

[91] Michels CA, Needleman RB. The dispersed, repeated family of MAL loci in Saccharomyces spp. Journal of bacteriology. 1984;157(3):949-52.

[92] Oda Y, Tonomura K. Detection of maltose fermentation genes in the baking yeast strains of Saccharomyces cerevisiae. Letters in applied microbiology. 1996;23(4):266-8.

[93] Hayford AE, Jespersen L. Characterization of Saccharomyces cerevisiae strains from spontaneously fermented maize dough by profiles of assimilation, chromosome polymorphism, PCR and MAL genotyping. Journal of applied microbiology. 1999;86(2):284-94.

[94] Bell PJ, Higgins VJ, Attfield PV. Comparison of fermentative capacities of industrial baking and wild-type yeasts of the species Saccharomyces cerevisiae in different sugar media. Letters in applied microbiology. 2001;32(4):224-9.

[95] Alves-Araújo C, Hernandez-Lopez MJ, Sousa MJ, Prieto JA, Randez-Gil F. Cloning and characterization of the MAL11 gene encoding a high-affinity maltose transporter from Torulaspora delbrueckii. FEMS yeast research. 2004;4(4-5):467-76.

[96] Hernandez-Lopez MJ, Prieto JA, Randez-Gil F. Isolation and characterization of the gene URA3 encoding the orotidine-5'-phosphate decarboxylase from Torulaspora delbrueckii. Yeast. 2002;19(16):1431-5.

[97] Sirenko OI, Ni B, Needleman RB. Purification and binding properties of the Mal63p activator of Saccharomyces cerevisiae. Current genetics. 1995;27(6):509-16.

[98] Wang J, Sirenko O, Needleman R. Genomic footprinting of Mig1p in the MAL62 promoter. Binding is dependent upon carbon source and competitive with the Mal63p activator. The Journal of biological chemistry. 1997;272(7):4613-22. 
[99] Ivorra C, Perez-Ortin JE, del Olmo M. An inverse correlation between stress resistance and stuck fermentations in wine yeasts. A molecular study. Biotechnology and bioengineering. 1999;64(6):698-708.

[100] Teunissen A, Dumortier F, Gorwa MF, Bauer J, Tanghe A, Loiez A, et al. Isolation and characterization of a freeze-tolerant diploid derivative of an industrial baker's yeast strain and its use in frozen doughs. Appl Environ Microbiol. 2002;68(10):4780-7.

[101] Thieringer HA, Jones PG, Inouye M. Cold shock and adaptation. Bioessays. 1998;20(1):49-57.

[102] Inouye M. Cold-shock response and adaptation. J Mol Microbiol Biotechnol. 1999;1(2):191.

[103] Sahara T, Goda T, Ohgiya S. Comprehensive expression analysis of time-dependent genetic responses in yeast cells to low temperature. J Biol Chem. 2002;277(51):50015-21.

[104] Rodriguez-Vargas S, Estruch F, Randez-Gil F. Gene expression analysis of cold and freeze stress in Baker's yeast. Appl Environ Microbiol. 2002;68(6):3024-30.

[105] Morris GJ, Coulson GE, Clarke KJ. Freezing injury in S. cerevisiae. The effects of growth conditions. Cryobiology. 1988;25:471-2.

[106] Kaul SC, Obuchi K, Komatsu Y. Cold shock response of yeast cells: induction of a 33 $\mathrm{kDa}$ protein and protection against freezing injury. Cell Mol Biol (Noisy-le-grand). 1992;38(5-6):553-9.

[107] Wolfe J, Bryant G. Freezing, drying, and/or vitrification of membrane- solute-water systems. Cryobiology. 1999;39(2):103-29.

[108] Rothstein R. Targeting, disruption, replacement, and allele rescue: integrative DNA transformation in yeast. Methods Enzymol. 1991;194:281-301.

[109] Schiestl RH, Gietz RD. High efficiency transformation of intact yeast cells using single stranded nucleic acids as a carrier. Curr Genet. 1989;16(5-6):339-46.

[110] Winzeler EA, Shoemaker DD, Astromoff A, Liang H, Anderson K, Andre B, et al. Functional characterization of the S. cerevisiae genome by gene deletion and parallel analysis. Science. 1999;285(5429):901-6.

[111] Dujon B. European Functional Analysis Network (EUROFAN) and the functional analysis of the Saccharomyces cerevisiae genome. Electrophoresis. 1998;19(4):617-24.

[112] Manivasakam P, Weber SC, McElver J, Schiestl RH. Micro-homology mediated PCR targeting in Saccharomyces cerevisiae. Nucleic Acids Res. 1995;23(14):2799-800.

[113] Wach A, Brachat A, Pohlmann R, Philippsen P. New heterologous modules for classical or PCR-based gene disruptions in Saccharomyces cerevisiae. Yeast. 1994;10(13):1793-808.

[114] Pacheco A, Almeida MJ, Sousa MJ. Improved gene disruption method for Torulaspora delbrueckii. FEMS yeast research. 2009;9(1):158-60.

[115] Esteve-Zarzoso B, Belloch C, Uruburu F, Querol A. Identification of yeasts by RFLP analysis of the 5.8S rRNA gene and the two ribosomal internal transcribed spacers. Int J Syst Bacteriol. 1999;49 Pt 1:329-37.

[116] Petersen KM, Moller PL, Jespersen L. DNA typing methods for differentiation of Debaryomyces hansenii strains and other yeasts related to surface ripened cheeses. International journal of food microbiology. 2001;69(1-2):11-24. 
[117] Guillamon JM, Sabate J, Barrio E, Cano J, Querol A. Rapid identification of wine yeast species based on RFLP analysis of the ribosomal internal transcribed spacer (ITS) region. Arch Microbiol. 1998;169(5):387-92.

[118] Querol A, Barrio E, Huerta T, Ramon D. Molecular monitoring of wine fermentations conducted by active dry yeast strains. Applied and environmental microbiology. 1992;58(9):2948-53.

[119] Guillamon JM, Cano J, Ramon D, Guarro J. Molecular differentiation of Keratinomyces (Trichophyton) species. Antonie van Leeuwenhoek. 1996;69(3):223-7.

[120] Fernandez-Espinar MT, Lopez V, Ramon D, Bartra E, Querol A. Study of the authenticity of commercial wine yeast strains by molecular techniques. International journal of food microbiology. 2001;70(1-2):1-10.

[121] Esteve-Zarzoso B, Fernandez-Espinar MT, Querol A. Authentication and identification of Sacharomyces cerevisiae 'flor' yeast races involved in sherry ageing. Antonie van Leeuwenhoek. 2004;85(2):151-8.

[122] Schuller D, Pereira L, Alves H, Cambon B, Dequin S, Casal M. Genetic characterization of commercial Saccharomyces cerevisiae isolates recovered from vineyard environments. Yeast. 2007;24(8):625-36.

[123] Schuller D, Valero E, Dequin S, Casal M. Survey of molecular methods for the typing of wine yeast strains. FEMS microbiology letters. 2004;231(1):19-26.

[124] Guillamon JM, Sanchez I, Huerta T. Rapid characterization of wild and collection strains of the genus Zygosaccharomyces according to mitochondrial DNA patterns. FEMS microbiology letters. 1997;147(2):267-72.

[125] Fernadez-Espinar MT, Esteve-Zarzoso B, Querol A, Barrio E. RFLP analysis of the ribosomal internal transcribed spacers and the 5.8S rRNA gene region of the genus Saccharomyces: a fast method for species identification and the differentiation of flor yeasts. Antonie van Leeuwenhoek. 2000;78(1):87-97.

[126] Lopez V, Querol A, Ramon D, Fernandez-Espinar MT. A simplified procedure to analyse mitochondrial DNA from industrial yeasts. International journal of food microbiology. 2001;68(1-2):75-81.

[127] Petersen KM, Jespersen L. Genetic diversity of the species Debaryomyces hansenii and the use of chromosome polymorphism for typing of strains isolated from surfaceripened cheeses. Journal of applied microbiology. 2004;97(1):205-13.

[128] Ribeiro GF, Corte-Real M, Johansson B. Characterization of DNA damage in yeast apoptosis induced by hydrogen peroxide, acetic acid, and hyperosmotic shock. Molecular biology of the cell. 2006;17(10):4584-91.

[129] Oda Y, Tonomura K. Electrophoretic karyotyping of the yeast genus Torulaspora. Lett Appl Microbiol. 1995;21(3):190-3.

[130] Wolf K, Del Giudice L. The variable mitochondrial genome of ascomycetes: organization, mutational alterations, and expression. Adv Genet. 1988;25:185-308.

[131] Ferguson LR, von Borstel RC. Induction of the cytoplasmic 'petite' mutation by chemical and physical agents in Saccharomyces cerevisiae. Mutat Res. 1992;265(1):10348.

[132] Bernardi G. The petite mutation in yeast. Trends Biochem Sci 1979;4:197-201. 
[133] Fekete V, Cierna M, Polakova S, Piskur J, Sulo P. Transition of the ability to generate petites in the Saccharomyces/Kluyveromyces complex. FEMS yeast research. 2007;7(8):1237-47.

[134] Spirek M, Soltesova A, Horvath A, Slavikova E, Sulo P. GC clusters and the stability of mitochondrial genomes of Saccharomyces cerevisiae and related yeats. Folia microbiologica. 2002;47(3):263-70.

[135] Soltesova A, Spirek M, Horvath A, Sulo P. Mitochondria--tool for taxonomic identification of yeasts from Saccharomyces sensu stricto complex. Folia microbiologica. 2000;45(2):99-106. 